\title{
1. Introduction: who are ethnic minorities and how well do they do in China? Xiaowei Zang
}

There are 56 state recognized ethnic groups (minzu 民族) in the People's Republic of China (PRC). The Han majority accounts for 91.5 per cent of the total population and the 55 ethnic minority groups make up 8.5 per cent. The ethnic minority groups have drawn a great deal of interest and curiosity from scholars, students, and the general public in the West. This is partly because they are socio-economically, culturally and ethnically different from Han Chinese. This is also because understanding ethnic minorities is central to understanding the Han majority, as people become more aware of an ethnic group's culture and tradition when they encounter and compare it with a different ethnic group. Furthermore, how the PRC treats its ethnic minorities can indicate how it will behave towards peoples outside China. The greater the role the PRC plays in the world economically and politically, the greater demand in the West for knowledge, analyses, and commentaries about ethnic minorities in China.

This edited volume attempts to explain who the ethnic minorities are and how they fare in China. In addition to offering general information about ethnic minority groups in the PRC, this volume discusses important questions on ethnicity in China: how are ethnic minorities represented in China? Are their gender norms different from those of Han Chinese? How serious is ethnic inequality in education and income? How well are minority cultures and languages preserved in China? What are the impacts of ethnic tourism on ethnic inequality and the promotion of minority cultures and languages in China? What does regional autonomy mean and how is it implemented in the PRC? Are ethnic minorities marginalized amid China's rapid economic growth? How well has the Chinese government protected minority rights and promoted multiculturalism? In what ways does China's ethnic policy affect its foreign policy and international relations?

To an extent, many of these questions have already been investigated by Western scholars. Articles on ethnic minorities in China frequently appear in top Asia/China journals such as The Journal of Asian Studies, Modern China, The China Quarterly, The China Journal, and The Journal of Contemporary China. Many leading university presses such as Harvard 
University Press and the University of California Press have regularly published monographs on ethnic minorities in China. These publications have offered detailed information, deep analyses, and reflective insights into the nature of minority ethnicity in the PRC. While this volume does not raise and examine new questions for the literature on ethnic minorities in China, it aims to advance this scholarship in two aspects. First, it consolidates knowledge scattered in different disciplines and provide readers with a multidisciplinary and multifaceted coverage of major issues in minority ethnicity in one single volume. Second, it addresses some conceptual/theoretical and methodological issues in the study of ethnicity in China and offers critical reflection on where the field has been and where it is going.

This volume is the outcome of a workshop on ethnic minorities in China held at the City University of Hong Kong in August 2015. The participants of the workshop included established scholars and emerging young talents in the field of Chinese ethnicity from Australia, Europe, Hong Kong, and the United States. They drew on methods and theoretical insights from different academic disciplines such as anthropology, cultural studies, history, and political science and exuberantly exchanged views on presentations made during the workshop. They recognized the complexities and subtleties in the empirical examinations and interpretations of sociocultural patterns and economic behaviours of non-Han peoples in the PRC, departing from Stalin's fourfold criteria of ethnic nationality (Stalin, 1953). In addition, they agreed to disagree. For example, while some workshop participants designate minz $u$ with the terms such as 'ethnic minorities', 'minority groups', 'non-Han peoples', or 'local peoples' in their chapters, others continue to use 'nationality' and 'nationality groups' in their contributions.

In this introductory chapter, I discuss who ethnic minorities in China are and how an individual's ethnic identity is determined. Next, I sketch out three major determinants of the well-being of ethnic minorities in the PRC: government ethnic policy, post-1978 market reforms, and the open door policy. I then offer an outline of each chapter. For convenience, I use the terms ethnic minority groups, ethnic minorities, and nationality groups interchangeably in this chapter.

\section{WHO ARE ETHNIC MINORITY GROUPS IN CHINA?}

To a large extent, ethnic groups are the product of the PRC's Ethnic Classification Project (Fei, 1980; Mullaney, 2004, 2011), much of which was carried out and completed in six months in 1953 (Caffrey, 2004: 253), resulting in a total of 38 ethnic groups in 1954. For unknown reasons, 
the number of ethnic groups in China increased to 53 after the second PRC census in 1964. Lhoba was then recognized as the 54th ethnic minority group in 1965 and the Jino of Yunnan was designated as the 55th minority group in 1979. In 1990, it was officially declared that China had 56 nationalities. The government has expressed no desire to increase the number of nationality groups in the PRC (Zang, 2015).

Mackerras (2015: 117) writes:

[T] here have been six censuses under the PRC, held in 1953, 1964, 1982, 1990, 2000 and 2010. In China the census includes ethnic breakdown and also gives aggregate figures for the ethnic minorities as a whole as well as their proportion in China's total population. The 1953 census showed the minorities at 34 million, or 5.89 per cent of the total population; that of 1982 put them at 66.4 million, or 6.62 per cent of the total, while the proportion in 1990 was 8.01 per cent of the total, which had by 2000 risen to 8.41 per cent or 106.46 million people.

According to Martina et al. (2011), the 55 ethnic minority groups accounted for 8.5 per cent of the population in the 2010 census.

The 55 ethnic minority groups are scattered in vast areas that cover some 60 per cent of the PRC's territory, much of which is China's border regions and strategically important for Beijing's relations with its neighbours such as Afghanistan, Myanmar, India, Kazakhstan, North Korea, Kyrgyzstan, Mongolia, Pakistan, Russia, Tajikistan, and Vietnam. The minority groups are concentrated in Inner Mongolia, Xinjiang, Ningxia, Guangxi, Tibet, Yunnan, Guizhou, Qinghai, Sichuan, Gansu, Hubei, and Hunan (Banister, 1992). Of all China's province-level administrative units, Yunnan province has the highest number of state-recognized minorities (25 ethnic groups), and almost one in three persons in the province are said to belong to one of the state-recognized ethnic minority groups (Mackerras, 2004b: 305). ${ }^{1}$

In China, one's ethnic status appears on his or her identity card, and his or her ethnic status depends on his or her parents' ethnic status. $\mathrm{He}$ or she is usually requested to provide information about his or her ethnic identity when applying to go to primary school, attend college, join the armed forces, or become a member of the Chinese Community Party (CCP), the ruling party in the PRC. An individual cannot change at will his or her ethnic status from Han to minority or from minority to Han. $\mathrm{He}$ or she can change his or her ethnic status if he or she meets official criteria and receives permission from relevant local government offices (Leibold, 2010b: 6). In the case of inter-ethnic marriages, parents can decide the nationality of their children, and the children themselves can choose their nationality at age 18 , which is their permanent choice of ethnic status (Guojiaminweigonganbu, 1990). 


\section{Handbook on ethnic minorities in China}

The minzu system set up after the 1953 Ethnic Classification Project has been a key institution in governance in the PRC, and at the same time has transformed the relationship between ethnic minority groups and the PRC state. Gros (2004: 291-2) writes insightfully: 'By way of their status as a full-fledged minzu, they have been able to reinforce their local identity, while also establishing a strongly held faith, among most, in the development and improvement of their social conditions.' This appears to be a kind of contractual acceptance that has been hinged on the state's promise to ethnic minority groups of better integration and improved access to resources.

The minzu system seems to be accepted as a legitimate institution in the PRC as few people have challenged the official categories of the 56 ethnic groups or questioned their individual ethnic identities. Many scholars both in and outside China have used the official categories in their research on ethnic minorities in the PRC. Lipman (1997: xxiv) thus claims that Beijing has been 'remarkably successful in imposing the language of the minzu paradigm on its entire population, including scholars and intellectuals of the "minority nationalities" themselves'.

\section{WHAT IS THE GUIDING PRINCIPLE FOR THE GOVERNANCE OF ETHNIC RELATIONS IN CHINA?}

China's nationality policy has been heavily influenced by Dr Sun Yat-sen (1866-1925), who in turn was influenced by Confucianism, which specifies that anyone can be a member of the Han community if he or she accepts Han culture (He, 2004: 113). Confucianism celebrates cultural, economic, and political intermingling among ethnic and cultural groups in order to form a harmonious Han community. It is believed that cultural outsiders can dispose of their uncivilized behaviour and thoughts and partake in Han society by learning, understanding, and adopting Han ways of life (He, 2004: 113-15; also Barbour and Jones, 2013: 102, 110; Dreyer, 1976: 1; Mackerras, 1984: 188; Wong, 2000: 54). In other words, Confucianism is not interested in providing a melting pot, and the Confucian concept of Han cultural community plays down ethnic criterion and encourages acculturation and eventual assimilation of non-Han peoples into Han society. Herberer (1989: 18, 131) contends that Confucianism 'despised these so-called "barbarians", but called for a policy of non-violent assimilation through the imposition of Han-Chinese values rather than through a policy of extermination' (also Wong, 2000: 53-4). He (2004: 112) argues that the key notion in this process of interface is called 'ronghe' (融合), that is, the amalgamation or fusion of the Han majority and the non-Han 
minorities in a process of Confucian cultural diffusion (also Sautman, 1999: 300).

Dr Sun Yat-sen was deeply influenced by Confucian ronghe ideology. Dr Sun and his comrades proposed a term 'zhonghua' (中华) by combining the 'middle kingdom' (zhongguo中国) with 'brilliant xia' (huaxia 华夏), and called the newly established Republic of China (ROC) 'Zhonghua minguo' (中华民国), which was 'the territories of the Han, Manchu, Mongol, Hui (Xinjiang) and Tibetans'. These groups were unified 'as one people, that is the unification of the Chinese nation (Zhonghua Minzu 中华民族)'. He insisted that the non-Han groups were the sub-branches of the Chinese nation, which would be assimilated into a 'single cultural and political whole', led by Han Chinese (Barabantseva, 2008: 570-72; Gladney, 1996: 79-85; Hyer, 2009: 259; Mackerras, 2011c: 114; Smith, 2004: 7; also Huang XT, 2002). Dr Sun proposed to use both ronghe and tonghua (同化) to achieve national unity via assimilation. Ronghe assumes relatively equal status between the Han people and nonHan peoples, whereas tonghua assumes a superior position of the former over the latter (Barabantseva, 2008: 571-2; Dreyer, 1976: 16; He, 2003: 226; Leibold, 2007: 113-75; Wang and Phillion, 2009: 2).

The CCP was set up with the support from the USSR in 1921. In its early years, the CCP dutifully observed the nationality policy of the USSR as part of its mission to establish communism in the world, where there was no social division based on class and ethnicity. Over times, however, it decided that Dr Sun's ronghe approach was a better principle to govern ethnic minorities in China and protect its power over and resources in minority areas. It thus promoted measures of acculturation and assimilation after the PRC was established in 1949 (Zang, 2015), insisting that the Han had formed a coherent nationality before 1949, whereas non-Han peoples had remained at feudal or pre-feudal levels of development. According to CCP propaganda, these minorities had been kept from becoming modern nations, and had been 'weak and small nationality' (弱小民族) and 'backward nationality' (落后民族). The CCP has used this storyline in the post-1949 era to justify the leadership of the Han in the Chinese nation (Barabantseva, 2008: 585; Hyer, 2006: 76-7). The official rhetoric claimed that non-Han peoples wanted to follow the CCP because they were members of the encompassing Chinese nation and were economically and culturally drawn to Han society (Zang, 2015).

Unsurprisingly, the 1953 Ethnic Classification Project was undertaken with the belief that 'backward' non-Han peoples required the CCP's leadership and 'advanced' Han socialist culture (Caffrey, 2004: 255-6). Soon after the Ethnic Classification Project was concluded, the Chinese government promoted Mandarin as a concrete step for non-Han peoples 
to acculturate into Han society and carried out development projects in minority regions to help non-Han peoples catch up with the Han and then move towards assimilation with the Han. The PRC's Premier Zhou Enlai said in 1957 that 'assimilation would not be welcome if it were achieved by force. Assimilation should be promoted if it were the outcome of mutual efforts of the majority and minority peoples. Successful examples of assimilation include the Hui people and the Manchu people' (He, 2003: 226; Leibold, 2007: 113-75; Zhu WQ, 2012).

Mao Zedong launched the Cultural Revolution in 1966 to oust his rivals from the power structure in China. He and his followers promoted extreme leftism to occupy the moral high ground in their campaigns. As ripples spread out across the nation, political radicalism began to dominate the field of minority governance, and the relatively mild pre-1966 approach towards ethnic minorities was abandoned. The 1975 constitution abolished the right of regional autonomy to minority nationalities because it would emphasize 'nationalism to the exclusion of patriotism', and create a national schism that would thwart the pace towards socialism in minority areas (Mackerras, 1995: 152; Sautman, 1999: 288; Zhu WQ, 2012). Minority cultures and religions were attacked, nationality policies were said to be no longer relevant, and forceful measures were taken in an attempt to assimilate minorities quickly (Clothey, 2001: 9; Herberer, 1989: 26; Leibold, 2010b: 17; Sautman, 1999: 300). Outright minority assimilation into Han society was justified because it would allegedly bring ethnic minorities out of backwardness to be in line with the advanced Han majority in the march towards communism.

The radical policy of the Cultural Revolution drove the Chinese economy to the brink of collapse and undermined the CCP's legitimacy in China. The death of Mao ended the Cultural Revolution in 1976. Since 1978 the CCP has stressed economic development to continue its reign in China (Zang, 2016). Economic growth has similarly become a major theme in China's nationality policy. Nevertheless, this change has not diminished the role of ronghe ideology in the government approach towards ethnic minorities to date, because the ultimate purpose of economic growth is to enable ethnic minorities to assimilate into Han society. The CCP has used 'the Chinese person' (中国人), as opposed to the Han, to include all ethnic groups within 'the Chinese nation' (中华民族). It has claimed that China is a united nation of many ethnic groups due to the 'outgrowth of the historical development of the past several thousand years', that China is a 'big fraternal and co-operative family composed of all nationalities', and that the ethnic minorities 'formed with Han Chinese a single, unbreakable unit' because of historical, cultural, and economic relations (Hyer, 2006: 76-7; Mackerras, 2011c: 114). For example, Zhu Weiqun, former 
executive deputy minister of the State Ethnic Commission, asserted that Tibetan culture was part of Chinese culture since the Yuan Dynasty (Zhu WQ, 2011: 14). The Ethnic Unity Textbook Compiling Team in China (Minzutuanjiejiaoyujiaocaibianxiezu, 2009: 17, 37, 79) claimed that 'Minzu extinction is an inevitable result of minzu self-development and self-improvement ... It is the final result of minzu development at its highest stage ... in this big minzu family every minzu group has a higher level of identification - the Chinese nation.' The reduction of the number of ethnic minority languages is said to be an 'inevitable outcome' of the increasing connections among different regions, and the expansion of Mandarin use is an inevitability of modernization (Xinjiangjiaoyuchubianshe, 2009: 94-5).

As another example, some Chinese scholars have claimed that many ancient nomadic peoples no longer exist because they had been 'sinicized' into Han people, and there shall be an eventual ronghe leading to the total disappearance of ethnic minorities in China in the future (Minzutuanjiejiaoyujiaocaibianxiezu, 2009: 17, 37, 79). Some top PRC officials have concurred that ronghe has been a frequent and common phenomenon in Chinese history. Zhu Weiqun (Zhu WQ, 2012) claimed, 'While assimilation shall not be achieved by administrative fiat, the government has to guide, promote, and lead the assimilative trend. One immediate measure the government shall adopt to promote assimilation is to abolish the ethnic identity in personal ID, stop setting up more ethnic autonomous areas, and promote the mixing of students of different ethnic groups' (also see Leibold, 2007: 113-75).

\section{POST-1978 MARKET REFORMS AND OPEN DOOR POLICY}

In addition to the CCP's ethnic policy, post-1978 market reforms have significantly affected the well-being of China's ethnic minorities. The imperatives of market reforms have aimed at competitiveness, efficiency and profitability at the expense of equality and social justice. To achieve the market reform imperatives, the CCP has shifted the responsibility of provisions in jobs, public health, pensions, education, elderly care and so on from the state to ordinary citizens and laid off a large group of workers in moneylosing state enterprises. The state has emerged from the reforms stronger in terms of its fiscal capacity, yet there have been consequences as market reforms have re-configured Chinese society. In the pre-1978 era, Mao promoted economic egalitarianism in an effort to eliminate 'three great equalities' - between worker and peasant, between city and countryside, and between mental and manual labour. China had become one of the most 
egalitarian societies in the world in the 1970s. In 1978, China's Gini coefficient was 0.22, one of the most equal ever recorded (Adelman and Sunding, 1987). After nearly 40 years of market reforms, China has become one of the most non-egalitarian countries in the world. One report claims that the Gini coefficient in China was around 0.30 in 1980, but by 2012 it had nearly doubled to 0.55, far surpassing the level of 0.45 in the United States (Xie and Xiang 2014). Another report asserts that the Gini coefficient in China was in fact 0.73 in 2012 (Zhang XY, 2014). Although many people have improved their living standards in the post-1978 era, reform programmes have generated widespread suffering and life disruption, affecting many social groups including ethnic minorities. The CCP has recognized these social issues and have adopted policies to improve its capacity to govern. Its policy package has included measures to improve social security and health care, the effort to build an 'eco-friendly society' and the initiative to build a 'socialist harmonious society'.

Yet these measures and campaigns are far from adequate. As a result, post-1978 market reforms have widened disparities, accentuated a sense of unfairness and sharpened social cleavages in China. Inequality has generated widespread discontent and anger among the poor, the weak and the dispossessed, including ethnic minorities, which have been unequivocally directed towards the state for its failure to safeguard social justice (Zang, 2008c). The post-1978 era has therefore witnessed repeated demonstrations and riots by ethnic minorities against the PRC government and the Han majority. Several contributors in this volume discuss ethnic inequalities, exploitation and marginalization in the post-1978 era.

Though many reform measures have negatively affected ethnic minorities in China, other reform measures such as the Great Western Development Strategy (Goodman, 2004b; Yang, 2004; Zeng, 2010) have aimed to reduce ethnic inequalities in China. In addition, the post-1978 open door policy has created an institutional environment in which different existing factors have been reconfigured, thus providing new internal dynamics for change. They have linked China and the world together, and the interplay between China and the world has produced a heterogeneous social landscape and an external dynamism for China's changes (Zheng Y, 2010: 800, 804). New ideas/concepts such as respect for diversity and multiculturalism have been diffused into Chinese society, changing the ways the Han majority thinks of and treats ethnic minorities. Minority ethnicity was perceptually related to backwardness and weakness. Since the 1990s, it has become popular to be 'ethnic' (Mackerras, 2011c: 113), partly reflecting the changing stereotypes of ethnic minorities in Chinese society. The benefits from government affirmative action have also contributed positively to the group worth and social status of ethnic minority 
groups. In a research project conducted in the Ehshi region in Hubei, it was found that local people thought of themselves as Han Chinese although they were officially designated as part of the Tujia people. They took Tujia status anyway because of the benefits associated with minority status (Brown, 2001: 59). It was reported in recent years that some Han students tried to pass as minority candidates in order to exploit the equal opportunity programme for university admissions.

Equally important, openness has provided a vital source of information for Chinese people including ethnic minorities. The Internet and the rapid development of blogs, Weibo (China's equivalent of Twitter) and Baidu (China's equivalent of Google) have increased citizen access to information. By the end of June 2014, China had 642 million Internet users, which is bigger than the combined total in the next three countries, the United States, India and Japan (China Internet Watch, 2014). Information is power. Increased exchange and interaction between China and the rest of the world have exposed ethnic minorities to what good governance is and how good governance works, thereby increasing their social and cultural capacity in their effort to reconstruct majority-minority relations. In particular, they have used concepts such as social justice and equality from the West in their struggle against discrimination and inequality in China. These new concepts have empowered ethnic minorities at the expense of the power of the state and the Han majority and made it increasingly difficult for government officials to be autocratic and conduct government business in an arbitrary and unaccountable way. Ethnic minority groups have also used social justice and equality to solicit international support and sympathy for their causes. In particular, Uyghurs and Tibetans have stressed ethnic discrimination and religious suppression to raise the awareness of their demands for greater autonomy (or independence) in Western societies.

The pressure from Western countries to promote human rights in the PRC has also contributed to the discourse over minority rights in China. Many foreign dignitaries have discussed issues related to ethnic minorities in meetings with Chinese officials, and there are also institutional arrangements as a major platform for the discourse on minority rights in China. For example, China and the EU have exchanged views regularly during the EU-China Dialogues on Human Rights including minority rights (Bi, 2011; Delegation of the European Union to China, 2011). Finally, the Chinese state's paradoxical enlistment of international development actors in the task of modernizing its minority areas such as Tibet (Zang, 2015) has allowed these NGOs to adopt international norms and practices on minority rights in devising development projects in minority areas in China (Williams, 2008). 


\section{CHAPTER OUTLINES}

The above discussion immediately leads to three questions about ethnicity in China. First, how well have ethnic minority groups done under the ronghe regime in the PRC? This is an important question because the PRC is not a democratic system. Thus, what the government does matters a great deal with the well-being of ethnic minorities in China. Second, how well have ethnic minorities fared in the post-1978 era? In particular, how have marketization and the open door policy influenced the well-being of ethnic minorities in the PRC? Third, how has China's ethnic policy affected its international relations since, in the era of globalization, what China does with regard to its ethnic minorities is not purely a domestic issue.

To partly address these questions, the next four chapters focus on some major ethnic minority groups in the PRC. These minority groups are chosen for detailed discussion in this volume because they are either subject to extensive research (e.g., minority groups in Southwest China and Hui Muslims) or the focus of international media when reporting ethnic minorities in the PRC (e.g., Uyghurs in Xinjiang and Tibetans in Tibet), or both (e.g., Uyghurs in Xinjiang and Tibetans in Tibet). Other ethnic minority groups are also important for research on ethnicity in China, and some of them are discussed in some detail in other chapters (e.g., Jankowiak and Shurentana and Mackerras in this volume).

In Chapter 2, Jianxiong Ma provides an overall view and general information about ethnic minorities in southwestern China. This region includes Sichuan Province, Guizhou Province, Yunnan Province, and Guangxi Zhuang Autonomous Region where a substantial number of ethnic minority groups live. Ma starts with a discussion of the geographic distribution of ethnic populations in this region, which he describes as one of the most culturally diverse areas in China and the world. He then examines the system of native chieftains in pre-modern times before giving a detailed description of ethnic identification and classification and the process of the establishment of minority autonomous governments in southwestern China. This chapter provides some background information for the discussions of some ethnic minorities in this region in the chapters by $\mathrm{Du}$, Schein and Luo, Oakes, and Ma.

In Chapter 3, Michael Dillon examines Chinese Muslims with emphasis on Hui in northwestern China in general and in the Ningxia Hui Autonomous Region in particular. He begins with a short discussion of the languages and cultures of the Chinese Muslims. He then outlines the origins of the Hui and Chinese Islam during the Tang Dynasty (618-906) and their developments during the Yuan Dynasty (1271-1368), the 
Ming Dynasty (1368-1644), and the Qing Dynasty (1644-1911) including Muslim rebels against the Manchus in 1862-1877. Next, Dillon mentions how Chinese Muslims have done in the PRC before he discusses the Hui in Ningxia, which he calls the titular homeland of Chinese Muslims. He is confident that the Hui, given their long tradition of involvement in trade and finance, will make major contributions to economic development in China.

In Chapter 4, Michael Dillon focuses on Uyghurs in the Xinjiang Uyghur Autonomous Region. He first outlines Xinjiang's geographical position before discussing various aspects of Uyghur culture including language, mosques and mazars. He then examines the relationship between the Chinese government and Uyghurs in Xinjiang, which has been marked by demonstrations, violence and resistance in the post-1990 era. The CCP has developed various policies and set up the religious affairs bureau, and the training of 'patriotic religious personnel' to maintain control in Xinjiang. It has also promoted economic development in the region. Yet ethnic violence has not abated because government responses have been simplistic and thus less than effective. Dillon concludes his chapter by arguing that the Xinjiang conflict is complex. It is political in the sense that demands for Xinjiang independence from China are raised. It is inter-ethnic as the core of the conflict is between Uyghurs and Han Chinese. Islam forms an essential part of that cultural conflict, and the majority of flashpoints between Uyghurs and Han Chinese have involved a dispute about ethnic and religious practice. It is not possible to disaggregate the ethnic, political and religious elements in the conflict: their relative importance varies from time to time but it is the combination of ethnic, political and religious factors that is so explosive. The chapter by Mackerras in this volume also discusses religious and other cultural issues among Uyghurs in Xinjiang.

In Chapter 5, Benno Ryan Weiner offers a historical overview of Tibet's position within China and China's position within Tibet. In the first section, he outlines the ethno-cultural dimensions of the Tibetan-speaking world, with a heavy emphasis on those regions within today's People's Republic of China. Second, he reviews the Tibetan Plateau's historical relationship with China-based states, stressing the ways in which both the CCP and advocates for Tibetan independence employ 'history' as a tool to make claims about Tibet's current international position. Weiner then examines the Tibetan Plateau's incorporation into the PRC during the Maoist period (1949-1976), focusing on the CCP's parallel but incomplete efforts to integrate Tibetans into the multinational, socialist Chinese nation. Finally, he investigates conditions in Tibetan regions during the post-1978 era. Over the last four decades the ideological demands and policy prescriptions of state socialism have largely been jettisoned. 
However, in light of major disturbances that erupted in the late 1980s and again in 2008, the CCP's shift to more developmental approaches of state building and national integration - even while maintaining the mechanism of state repressions - has not been very successful in convincing many Tibetans that they have an equal stake in the Han-dominated, multinationality Chinese nation-state. The chapter by Mackerras in this volume also discusses religious and other cultural issues among Tibetans in Tibet.

In order to understand minority ethnicity and ethnic conflicts in the post-1978 era mentioned above, it is necessary to examine ethnic policies and their impacts on ethnic minority groups in China. Thus, the next three chapters discuss various government policies on the governance of minority ethnicity in the PRC. In Chapter 6, Minglang Zhou points out that the accommodation of multiculturalism in China has been a serious challenge since 1949. He examines, in terms of the concept of citizenship, how China entertained multiculturalism in the Soviet model of multinational state building between 1949 and the 1990s and how China has accommodated multiculturalism in its new Chinese model of one nation with diversity since the late 1990s. According to Zhou, the Soviet model selectively practiced citizenship and created more particularism than universalism, resulting in uncompromising conflicts between ethnic identities and the unitary national identity. The Chinese model in association with the cultural pluralist approach to citizenship appears to be a viable alternative to the Soviet model in bridging minority cultures and the mainstream culture and in coordinating ethnic identities and the inclusive Chinese national identity if China improves its practice of citizenship. Multiculturalism is model-specific in China.

In Chapter 7, Hongyi Lai claims that the ethnic issue has a broad ramification for China's national unity and security. During most of the post-1949 period in ethnic areas under its leadership the CCP has practiced so-called regional ethnic autonomy (REA) in order to appease ethnic aspiration while securing national unity under a strong central government. REA can be understood as limited administrative autonomy and was inspired by the ethnic policy of the Soviet Union, imperial China and CCP practices in the 1940s. By 2008 PRC had 155 ethnic autonomous areas (EAAs) at the provincial, prefectural and city levels. The institutions and policy associated with REA has undergone changes over the decades, but the political objectives have remained largely unchanged. By granting ethnic areas limited administrative autonomy and ethnic minorities favourable economic and social treatments, the CCP aims to maintain a unitary multi-ethnic nation-state.

In Chapter 8, James Leibold describes the PRC as the most consequential and extensive regime of minority entitlements in the world. The 
Chinese state provides a range of preferential treatment for its more than one million ethnic minorities - such as territorial autonomy, special cultural rights, marriage and reproductive exceptions, political and employment quotas, yearly economic aid money and additional educational resources - with the stated aim of closing the development gap with the Han majority. Leibold argues that in contrast to the moral and ideological underpinnings of the affirmative action debates in the West, where social equality and cultural recognition are chief concerns, minority preferences in China are viewed primarily as tools of statecraft: a set of pragmatic and instrumental strategies for upholding territorial sovereignty, preserving social stability and ultimately protecting the power of the Han elite. In principle, minority entitlements do not seek to usher in a more diverse, tolerant and inclusive society in China; rather their goal is the maintenance of the political status quo through the co-option of a core group of minority elites/middle class. Leibold argues that this system of ethnic clientalism lends a degree of stability and legitimacy to Chinese Community Party rule, while government handouts also keep most minorities out of abject poverty, even if they still struggle to keep up with their Han counterparts.

The next five chapters discuss how government policy has affected ethnic identities and cultures in China. In Chapter 9, William Jankowiak and B Shurentana discuss research on urban Chinese ethnicity, using urban Mongols as a case study. They argue that ethno-politics are grounded in two contradictory philosophies that often give rise to competing policies in China: the upholding of the ethnic group as well as the individual right to achieve prominence within the established social order. The issue of the relevant strength of Chinese nationalism as opposed to minority nationalism within a given group is largely an unexplored territory. Next, Jankowiak and Shurentana provide an overview on trends and findings taken from research on a variety of Chinese ethnic groups living in cities. They then focus on the diversity found in urban Mongols life-orientations as it is organized around notions of ethnic integrity, friendship, ethnic interaction and historical remembrance. Finally, Jankowiak and Shurentana explore the criteria Mongols use to signal Mongolian identity in a fluid market society.

In Chapter 10, Colin Mackerras studies minority languages and cultures. Culture is defined in terms of attitudes to life and values, and in behavioural terms. Cultures are learned and passed on from generation to generation, and subject to change. Mackerras outlines government policy towards ethnic minority languages and, with some focus on the twentyfirst century, discusses the situation for minority languages. He suggests that minority languages are not doing well due to the gathering pace of the spread of Mandarin and Chinese modernization. He also covers topics such as the use of minority languages in the education system. Next, 
Mackerras discusses minority religions in China, especially Islam and Tibetan Buddhism. He takes up some historical factors but focuses on the present era, finding that both Islam and Tibetan Buddhism are very much alive and possibly even strengthening. Mackerras then examines material about the state of Christianity among the minorities and some other traditional faiths such as shamanism. He also discusses the situation for the arts among the minorities, including the ways they have functioned in society and become politicized and a form of propaganda for the government since 1949. His focus is mostly on architecture and the performing arts, mainly traditional songs and dances, but also two specific forms, namely the Twelve Muqam of Uyghurs and the ache lhamo of Tibetans. Finally, Mackerras takes up the complex interrelationships between minority cultures and politics as well as issues of cultural survival. He argues that there is no deliberate government attempt to destroy or undermine minority religions, languages or cultures. However, the process of modernization is gathering momentum everywhere in China and is inimical to traditional cultures. This is especially the case in a context where state policy and realities are dominated by one ethnic group with a strong population majority and cultural tradition.

In Chapter 11, Shanshan Du argues that in mainstream academia and popular discourses, gender norms in China are erroneously intertwined with 'Chinese patriarchy', which also serves as a vital social category in contemporary analysis of gender relations. Du challenges the concept of 'Chinese patriarchy' by stressing the diversity and dynamics of gender norms among ethnic minorities in China. She first offers a sketch of gendered cultural heritages of ethnic minorities in the context of the invasive influence of patriarchy during their interactions with Han Chinese and the state. She shows that minority peoples have always been actively appropriating, negotiating, contesting and resisting the powerful encroachment of Han patriarchy. As a result, diverse gender systems of minority heritages have been sustained to varying degrees, and continue to compete with Han patriarchy, amidst radical sociocultural transformations across China since 1950s. Next, Du examines the gender norms among the Lahu and the Mosuo. She shows the ways by which the cultural heritages of both societies effectively promote gender egalitarianism that is grounded in very different social structures and gender ideals. By exploring the sociocultural principles underlying the Lahu and Mosuo model of gender egalitarianism, she highlights the theoretical significance of embracing an ethnic dimension in the study of gender norms in China, and cross-cultural studies of gender relations in general.

In Chapter 12, Louisa Schein with Luo Yu examines how ethnic minorities have been portrayed in public culture and the effects of the portrayals 
in China, using historical specificity, political economy and a contingent approach to study social hierarchy. She argues that such hierarchy is undergirded by discourses of superiority - or what she calls 'supremacism' - within the Chinese social field. The symbolic counterpart of minorities has been the monolith Han/state/urban/intellectual/elite/masculine/modern/civilized/centre and so on, which identifies a complementary signifying chain in which representations of the non-Han would bundle the feminine, the natural, the primitive and myriad other associated attributes. She addresses this contrast by examining a process of 'internal orientalism' that arose out of the perceived void at the core of Chinese national identity that had developed in reaction against the suppressions of the Cultural Revolution combined with the import of Western culture in the reform era. Through keying minority representation to specific social shifts in the last several decades, she asks: who, exactly, is doing the othering at given periods in time and in specific instances? In addition, she asks: when minorities represent themselves, what is reworked and what is reiterated from dominant culture? Schein considers two case studies of minority self-representation and then goes on to entertain the possibility of what she glosses as a 'post-alteric' social imaginary that may be on the rise in the public culture of China's twenty-first century.

In Chapter 13, Timothy Oakes presents several key issues concerning the study of ethnic tourism in China today. Chinese-language tourism scholarship has exploded since the mid-2000s, and much of it has focused on interethnic struggles over culture, identity, the meanings of modernization and politics of representation. Oakes argues that the critical issues need to be addressed within a dynamic context of rapid transformation in Chinese tourism more broadly. That context has been dominated by the rise of independent tourism and leisure consumption in China. Oakes suggests that Chinese ethnic tourism can be approached and understood as a kind of urbanization. Much of his review is influenced by his own long-term experience studying ethnic tourism in one particular region of China, Guizhou Province. For this reason, ethnic tourism in southwestern China is emphasized in this chapter. Oakes shows that in a clear reversal of the Mao era's emphasis on urban centres as beacons of progressive socialist modernity in a wilderness of 'ethnic backwardness', cities and towns have been rebranding themselves - and reconstructing their built landscapes - as displays of village-style ethnic architecture and culture. As this has happened, ethnic tourism in China has perhaps become less about experiencing the exotic otherness of China's minorities, and more about providing a colourful backdrop for China's growing leisure consumption market. At the same time, ethnic tourism has served as a conduit for greater state control over community-held assets, leading to alienation 
on multiple levels. Oakes also raises a question about the role of ethnic tourism in the broader pattern of ethnic cultural revival in the reform era.

The next three chapters shift our attention from ethnic cultures to ethnic inequality and marginalization in China. In Chapter 14, Yangbin Chen studies inequality in education between China's ethnic minorities and the mainstream Han population. He first reviews the Chinese-language and English-language literature on this topic since the early years of economic reform in the 1980s. He adapts an analytical framework based on the work of Buchmann and Hannum (2001) on interpreting education and stratification in developing countries. He discusses ethnic inequality in Chinese education from four main perspectives. The first is the macrostructural forces that shape the inequality, such as geography, history and policies. The second is the system of the family-school-ethnic community, where the ethnic inequality in education takes place in an everyday setting. The third perspective involves minority cultures with a focus on minority bilingual education. The last standpoint examines the effects of the ethnic inequality process in education, where the disparity of educational attainment between ethnic minorities and Han Chinese is investigated. Chen suggests that a better understanding of ethnic inequality in education in the Chinese context will grapple with three essential issues. First, the formation of this inequality is a process and not isolated from other social, economic and cultural inequalities created by China's transformation to a market economy. Second, attention to ethnic inequality in education has shifted from basic education before 2000 to higher education after 2000. Last, 'ethnic inequality in Chinese minority education' is a relative designation that needs to be perused carefully and by individual ethnic groups.

In Chapter 15, Björn Gustafsson surveys research that addresses the existence and magnitude of disparities in economic well-being in China between ethnic minorities and the majority Han group, and attempts to throw light on the reasons for the gaps. According to Gustafsson, in rural China, income differs greatly between locations and most of China's rural minorities live in places with low average income. This is one important background reason why most of China's rural ethnic minorities lag behind the Han majority in terms of both the size of the average per capita income and higher poverty rates. In addition, in some but not all rural locations, ethnic minority households receive lower incomes than Han majority households. Ethnic minorities make up a considerably smaller proportion of the population in urban than in rural areas. Policies of affirmative action have given urban ethnic minority workers priority for employment in jobs funded by public resources. However, post-1978 market reforms have resulted in a major job decline in the public sector. Gustafsson also reports that China's various ethnic minorities differ from each other when it comes 
to economic well-being. For example, members of the Korean minority living in urban China receive on average higher wages than their Han peers. Conversely, many ethnic minorities in the rural southwest of China are disadvantaged relative to rural inhabitants in the rest of China and to Han people residing in the same location and having the same characteristics.

In Chapter 16, Jianxiong Ma analyses the issue of ethnic marginalization and why minority responses to ethnic marginalization happened in the last several decades in the southwest frontier of China, using the Lahu group as a case study. The Lahu is an ethnic group in south Yunnan province, mainly inhabiting the mountain areas on the borderland between Yunnan and Burma. Since 1953, the Lahu has been identified as the official Lahu nationality and a Lahu autonomous county was established. However, there was an inadequate supply of educated Lahu elite. The government has not addressed this issue. It has instead focused on poverty reduction projects. As a result, the Lahu's position in the local government hierarchy has been 'hijacked' by local Han elites. The civil service examination for cadre recruitment has further narrowed the Lahu's participation into local decision-making. This may be a major reason why local developments have been slow since economic growth in the local region has not been a major concern or has been effectively promoted. This in turn has strengthened the Han discourses of Lahu backwardness. As a result, the Lahu people has suffered from the pain of being the Lahu. In the last three decades, more and more Lahu women have married Han peasants and the rate of the Lahu suicides, in order to move to the world of the dead in their religious belief, is increasing. Moreover, more and more Lahu people have become addicted to alcohol in order to escape the shame and pain associated with being the Lahu.

In Chapter 17, Kam-yee Law and Kim-ming Lee provide an updated evaluation of the overall performance of integration policies by focusing on South Asian minorities (i.e., Indians, Pakistanis and Nepalese), who had been in Hong Kong for over 170 years but continue to live under disadvantaged conditions. The implementation of integration policies, focusing on the experience and constraint of the non-governmental organizations (NGOs) as implementing agents of the policies, is also examined because South Asians are the main targets of these social services. Law and Lee find that in general the integration policies seem to be working, but not well enough to integrate ethnic groups into Hong Kong society. Racial discrimination in Hong Kong has been reduced, though many South Asians are still confronted with various forms of discrimination in their daily life. Many South-Asian lower-strata people are still locked in low-paid elementary jobs. Although the educational attainment of Pakistanis and Nepalese has been significantly raised, they still have fewer 
chances to enter universities because of their poor command of Chinese language. Without post-secondary qualification, they have difficulties improving their living through getting well-paid jobs in Hong Kong. Social interactions between Chinese and South Asians have remained at a low level. The government has adopted an assimilation-oriented approach to enable South Asians to cross the racial boundary and enter mainstream society by enhancing their Chinese language ability and human capital, but it has not done adequately to encourage Chinese to understand and respect South-Asians' cultures and lifestyles. Moreover, the government policies have failed to address structural inequalities between Chinese and South Asians. Law and Lee also identify five types of NGOs that serve ethnic minorities, however, all of them have limited capacities to help South Asians integrate into Hong Kong society.

In Chapter 18, Michael Clarke argues that the PRC's ethnic minorities have been a significant factor in the PRC's foreign relations. He first defines the nature and scale of the challenge posed by an ethnic minority as a function of the interplay of five major factors: the historical relationship between the ethnic group and the Chinese state; the geographic concentration of an ethnic minority; and the degree of acculturation to the dominant Han society; external great power support; and mobilized diasporas. Next, Clarkes provides an overview of how the IR and foreign policy analysis literature has approached the relationship between ethnic minorities and foreign policy. He then surveys the relationship between ethnicity and foreign policy in the Chinese context to determine the utility or otherwise of the existing IR and foreign policy analysis literature. Clarke then examines China's foreign policy via a case study of the impact of the Xinjiang and Uyghur issues. The challenge to the PRC has shifted from the 'bounded' problem of 'separatism' (a territory and sovereignty-focused political phenomena) towards a spatially and temporally 'de-bounded' one in which the CCP simultaneously confronts multiple manifestations of Uyghur nationalist/separatist aspirations locally (i.e., within Xinjiang and the PRC more broadly), regionally (i.e., in Central and South Asia) and globally (i.e., through activism of the Uyghur diaspora). This shift shows how the Xinjiang and Uyghur issues have been internationalized and have complicated China's foreign relations.

\section{SUMMARY}

This volume attempts to consolidate knowledge on minority ethnicity in China scattered in different disciplines and to provide readers with a multidisciplinary and multifaceted coverage of major issues in minority eth- 
nicity in the PRC. It also attempts to address some conceptual/theoretical and methodological issues in the study of ethnicity in China and offer critical reflection on where the field has been and where it is going. It is the first of its kind in the field of ethnicity that traces the historical evolutions and profound impacts of the government policy and social changes on ethnic minorities in China.

This introductory chapter shows that ethnic issues are the outcome of state intervention in China. The government policy has institutionalized ethnic boundaries and defined the meanings of ethnicity in the PRC, and this policy power has manifested itself by officially placing individuals under different ethnic group category and incorporating ethnic categories and rewards for minority ethnicity into the politico-bureaucratic system in China (Mullaney, 2004: 208). In addition, post-1978 reforms and the open door policy have increasingly influenced the well-being of ethnic minorities in the PRC. The economic reforms have introduced market forces into Chinese society and widened the gap in labour market outcomes between the Han majority and ethnic minority groups since 1978. At the same time, new concepts including multiculturalism, equality, social justice and respect for diversity have been diffused into the discourse on minority ethnicity in China thanks to the open door policy in the post-1978 era.

The contributors of this volume have examined how state policy, market reforms, and new ideas/concepts have affected ethnic minorities in China. They have turned this edited volume into a convenient reference, offering an overview of key issues in research on ethnic minorities in China. They cover a wide range of topics including nation-building and multiculturalism in China, minority cultures and languages, representations of minorities, minorities and urban life, gender norms among ethnic minorities, ethnic inequalities in education and labour market outcomes, ethnic tourism, ethnic marginalization, affirmative action and minority rights, Tibet, minorities in Hong Kong, and the impact of ethnic minorities on China's foreign policy. Hopefully, this volume will enrich knowledge on minority ethnicity in China and be a key reference in future research on ethnic minorities in China.

\section{NOTE}

1. Readers interested in the distribution of ethnic minorities in the PRC can read the 'Interactive Map of Minorities in China', The New York Times, 10 July, 2009, available at: http://www.nytimes. com/interactive/2009/07/10/world/20090711-xinjiang.html?_r=0. 